\section{$\underset{\substack{\text { hommes } \\ \text { \& migrations }}}{ }$}

\section{Hommes \& migrations}

Revue française de référence sur les dynamiques

migratoires

1307 | 2014

L'Afrique qualifiée dans la mondialisation

\title{
Danielle Mitterrand et les Kurdes : le rêve d'une Première dame
}

Michel Joly

\section{OpenEdition \\ Journals}

Édition électronique

URL : http://journals.openedition.org/hommesmigrations/2896

DOI : 10.4000/hommesmigrations.2896

ISSN : 2262-3353

Éditeur

Musée national de l'histoire de l'immigration

Édition imprimée

Date de publication : 1 juillet 2014

Pagination : 134-135

ISBN : 978-2-919040-28-5

ISSN : $1142-852 X$

Référence électronique

Michel Joly, «Danielle Mitterrand et les Kurdes : le rêve d'une Première dame », Hommes \& migrations [En ligne], 1307 | 2014, mis en ligne le 15 janvier 2015, consulté le 22 septembre 2020. URL : http:// journals.openedition.org/hommesmigrations/2896 ; DOI : https://doi.org/10.4000/ hommesmigrations.2896 


\section{DANIELLE MITTERRAND ET LES KURDES \\ LE RÊVE D'UNE PREMIĖRE DAME}

MICHEL JOLI, secrétaire général de France Libertés - Fondation Danielle-Mitterrand.

e rêve de Danielle Mitterrand est un rêve qui Lvient de loin. C'est un rêve qui s'enracine dans son enfance; il a pour nom "liberté". Un rêve porté par son père instituteur républicain, qui lui apprit très jeune à dire non et à contenir son romantisme naturel, et par une mère qui organisait l'accueil des résistants des maquis de Cluny. À 17 ans, Danielle était agent de liaison et recherchée comme terroriste... Puis, à la Libération, elle fut médaillée de la Résistance.

Autodidacte cultivée, passionnée par la peinture et les livres d'art, Danielle découvrit très jeune les allées du pouvoir aux côtés de son mari, François Mitterrand. Il est certain que l'exemple de son père, l'enseignement de sa mère ainsi que son engagement dans la Résistance l'avaient prédisposée à un destin exceptionnel. "Je savais que mon chemin me conduirait inéluctablement à dénoncer les atteintes à l'intégrité de la vie et à la dignité. Toute ma vie, je résisterai contre ce qui ne relève pas de l'intérêt général", déclarait-elle.

Pour Danielle, le rôle d'une Première dame était simple : mettre son pouvoir d'influence au service des sans-voix, des désespérés, des minorités et des exclus.

Dans les années 1980, défendre les droits de I'homme et les libertés n'était pas chose facile. Dans une situation internationale bloquée, le verrouillage, à l'Ouest comme à l'Est, était total. Les actions sur le terrain se révélaient impossibles car les règles du jeu diplomatique étaient très contrôlées. On ne pouvait s'intéresser qu'à des situations individuelles : peine de mort arbitraire, injustice, et signer des pétitions souvent sans effet. Beaucoup de leaders se tournaient alors vers des personnalités non gouvernementales capables de les entendre et de relayer leur message.

C'est ainsi que Danielle Mitterrand trouva sa place dans une forme de diplomatie d'influence, toujours en marge mais toujours en accord avec le président de la République.

Tout commença avec le drame kurde. En 1988, la fondation France Libertés est encore toute jeune et inexpérimentée. Or la détermination de Danielle est totale, à la hauteur de l'immense indifférence de la communauté internationale. Elle vient de découvrir le génocide kurde, "I'Anfal", les camps de réfugiés en Turquie de Mardin, Diyarbakir et Mush, les témoignages terrifiants. Elle décide alors, contre l'avis de tous, de s'engager pleinement dans une opération de "diplomatie parallèle" dictée par la compassion, l'amour et la révolte.

Dès octobre 1989, contre l'avis des diplomates et en dépit de la colère de Saddam Hussein, elle organise à Paris un colloque intitulé "Les Kurdes l'identité culturelle, le respect des droits de l'homme", réunissant des représentants de plus de 20 pays. Cet intitulé faisait autant référence au bicentenaire de la Déclaration universelle des droits de l'homme qu'à la situation des Kurdes. 
Danielle Mitterrand sous la tente d'une famille de réfugiés au camp de Mardin en Turquie, 1989 (c) ARCHIVES

Il fallait donc aborder le sujet avec prudence! Or, quand Danielle prit la parole, ce fut sans détour : "Je suis fière d'être présente auprès de nos amis kurdes quand ils défendent leur identité et revendiquent leur patrimoine culturel! (...) Sans pause ni trêve, France Libertés et sa présidente parleront pour ces femmes et ces enfants parqués dans des camps, dont le seul crime est d'être kurdes. (...) Sans pause ni trêve, je défendrai le droit de s'exprimer, le droit de se réunir. (...) Je hais les armes et la violence parce que la force de l'homme juste est dans son pouvoir de dire, de témoigner, de convaincre et d'organiser la solidarité en réponse à la répression."

Cette prise de parole constituait un cri d'alarme bien inhabituel dans la bouche d'une Première dame en exercice.

Après cela, s'organisa fin 1989 l'accueil en France de près de 1000 réfugiés kurdes, en accord avec le Président et le gouvernement.

L'opinion publique prit l'habitude de tourner les yeux vers le Kurdistan et Danielle décida en avril
1991 de rencontrer ce peuple martyr sur place, dans le pire moment de son histoire, sur les chemins de l'exode, fuyant les persécutions de Saddam Hussein. Elle fut accueillie clandestinement, sur la frontière iranienne, à Haj Omran, par les dirigeants de la résistance kurde, dont Massoud Barzani, sur une bande de terrain réputée déminée.

Avec le recul, on comprend que l'admiration des Kurdes pour Danielle soit à la hauteur de son intrépidité !

C'est clairement sous la pression de Danielle Mitterrand que la France a enfin joué un rôle indispensable dans l'adoption de la résolution 688 assurant la protection du Kurdistan et l'évacuation des troupes de Saddam Hussein.

En juillet 1992, Danielle était présente à Erbil, parmi ses amis kurdes, pour assister à la constitution du premier gouvernement d'union nationale. Au cours de ce déplacement, elle fut victime d'un attentat qui fit plusieurs morts. C'est à partir de cette date que la fondation France Libertés s'impliqua pendant près de dix ans dans une action prioritaire : participer à la reconstruction d'un pays ravagé, endeuillé, sans villages, sans écoles, sans hôpitaux.

Afin d'assurer la rentrée scolaire de 1992, la fondation fit imprimer en France, à l'Imprimerie nationale, des centaines de milliers de manuels scolaires acheminés par camions. La reconstruction des écoles et l'aide alimentaire mobilisaient également toutes les énergies et les réseaux de la fondation.

C'est ainsi que Danielle connut une nouvelle résistance, une nouvelle libération, une nouvelle indépendance. Son combat pour la cause kurde était aussi un retour à l'époque où l'insouciance et le danger avaient modelé son caractère. Elle ne fit jamais la différence entre les résistants de Cluny et ceux des montagnes kurdes. Les uns et les autres étaient pour elle les acteurs d'un même rêve : celui de la liberté. 